\title{
Evaluation of the changes in working limits in an automobile assembly line using simulation
}

\author{
Luís Ferreira $^{(1)}$, E. Ares Gómez ${ }^{(2)}$, G. Peláez Lourido ${ }^{(2)}$ \\ A. Resano Lázaro ${ }^{(3)}$, C. J. Luis Pérez ${ }^{(3)}$, Benny Tjahjono (4) \\ ${ }^{(1)}$ Escola Superior de Estudos Industriais e de Gestão, Instituto Politécnico do Porto, \\ Portugal, Email: Luispintoferreira@eu.ipp.pt \\ (2)Área Ingeniería de los Procesos de Fabricación, Universidad de Vigo, \\ Spain, Email: enrares@uvigo.es, gupelaez@uvigo.es \\ ${ }^{(3)}$ Departamento de Ingeniería Mecánica, Energética y de Materiales, \\ Universidad Pública de Navarra, Spain \\ ${ }^{(4)}$ Manufacturing Department, School of Applied Sciences , \\ Cranfield University, UK
}

\begin{abstract}
RESUMEN
El objetivo del trabajo presentado consiste en el desarrollo de un sistema de apoyo a la toma de decisiones, basado en modelos de simulación de eventos discretos, de una línea de montaje de automóviles, que fue implantado en un entorno de simulación Arena y enfocado a una clase muy específica de líneas de producción con una configuración en red de cuatro bucles cerrados. Esta distribución en planta refleja una de las configuraciones más comunes de líneas de transporte de automóviles para montaje y pre-montaje. La suma del número de palets en los almacenes intermedios, se mantiene constante, excepto en el cuarto bucle cerrado, en el que depende de la proporción de coches de cuatro puertas $(x)$ implementado entre las estaciones de desmontaje y montaje de puertas en la carrocería. Algunas ecuaciones de control de los cuatro bucles cerrados no son compatibles con las capacidades de varios almacenes intermedios para ciertos valores de la variable $\mathrm{x}$. Esta incompatibilidad muestra como la línea de montaje no puede funcionar en la práctica para $x<0,37$ y para $x>0,97$ en un régimen estacionario, debido al fenómeno de llegada nula o de falta de suministro en las máquinas de la línea de producción. Se ha evaluado el impacto del números de palets, que circulan en el primer bucle cerrado, en el rendimiento de la línea de producción, considerando el número de coches producidos/hora, con el fin de mejorar la disponibilidad del sistema de fabricación para cualquier valor de $\mathrm{x}$. Hasta donde hemos podido conocer, hasta la fecha actual, no existen trabajos en la literatura especializada que presenten estos resultados.
\end{abstract}

Palabras clave: Líneas de Producción, Bucles Cerrados, Simulación

\begin{abstract}
The aim of the work presented in this paper consists of the development of a decision-making support system, based on discrete-event simulation models, of an automobile assembly line which was implemented within an Arena simulation environment and focused at a very specific class of production lines with a four closed-loop network configuration. This layout system reflects one of the most common configurations of automobile assembly and preassembly lines formed by conveyors. The sum of the number of pallets on the intermediate buffers, remains constant, except for the fourth closed loop, which depends on the four-door car ratio $(x)$ implemented between the door disassembly and assembly stations of the car body. Some governing equations of the four closed-loops are not compatible with the capacities of several intermediate buffers for certain values of variable $x$. This incompatibility shows how the assembly line cannot operate in practice for $x<0,37$ and for $x>0,97$ in a stationary regime, due to the starvation phenomenon or the failure of supply to the machines on the production line. We have evaluated the impact of the pallet numbers circulating on the first closed-loop on the performance of the production line, translated into the number of cars produced / hour, in order to improve the availability of the entire manufacturing system for any value of $x$. Until the present date, these facts have not been presented in specialized literature.
\end{abstract}

Keywords: Production Lines, Closed-Loops, Simulation 


\section{Introduction}

Simulation is one of the support tools in the decision-making process, which allows for the projection and analysis of performance in systems and complex processes. Simulation can be seen as the construction process of a model representing a real system, as well as that of undertaking experiments using the same model, with the purpose of better understanding its behaviour and evaluating the impact of alternative operational strategies [1-5].

The work presented in this paper consists of the development of a decision-making support system, to analyse and optimize multistage multiproduct production lines. This was based on a real case (a production line at Volkswagen Navarra S.A, Pamplona, Spain), which was mathematically modelled by Resano [6] and supported by discrete-event simulation models. These were implemented in an Arena simulation environment and were targeted at a rather specific class of production lines, with a network configuration of four closed-loops, which is very common in the automobile sector. One aims to address the aspects not covered in the Resano [6] study, where the author formulated the first analytical model for an assembly line in the automobile sector with a network configuration consisting of four closed-loop machines and intermediate buffers; the latter comprise conveyors which, at a determined speed, transport assembly pallets that are not univocally interrelated. Both in the analytical model, as well as in the simulation model presented here, one is able to analyze the blockage and starvation phenomena of machines on a complex production line. The proportion of four-door cars between the door disassembly and assembly stations is also considered. Regardless of the importance of the development of different models in a simulation environment, allowing for the analysis and optimization of these types of automobile assembly lines, there is no knowledge of any other study in specialist literature that takes all these factors into account, though they are especially relevant in the performance of these types of manufacturing lines.

\section{Model of the Assembly Line}

Figure 1 represents the main automobile line, as well as the door and front axle preassembly lines, as a network of four closed-loops of machines (M) and intermediate buffers (B) formed by conveyors. The time cycle for each machine is fixed and deterministic. Each of the intermediate buffers possesses a limited capacity, in accordance with the number of pallets it can contain, as follows: $\mathrm{B}_{1,2}=80$ pallets, $\mathrm{B}_{2,3}=37$ pallets, $\mathrm{B}_{3,4}=30$ pallets, $\mathrm{B}_{4,1}=123$ pallets, $\mathrm{B}_{2,5}=330$ pallets, $\mathrm{B}_{5,6}=39$ pallets, $\mathrm{B}_{6,4}=161$ pallets, $\mathrm{B}_{4,2}=124$ pallets, $\mathrm{B}_{3,7}=157$ pallets, $\mathrm{B}_{7,3}=135$ pallets.

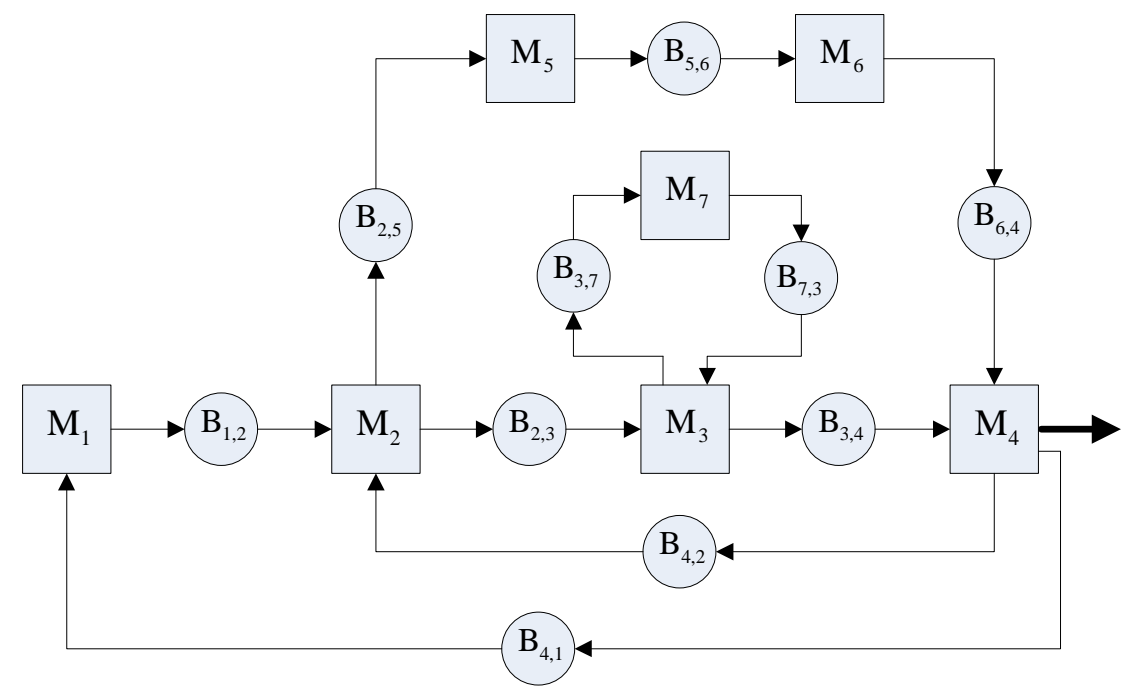

Figure 1. Main automobile assembly line and preassembly lines [6]

The sum of the car bodies, doors and front axle assembly pallets stored in each of the intermediate buffers of the three first closed-loops remains, respectively, constant at any time and is defined by Equations (1) to (3). This fact, as well as other analyses undertaken to evaluate the influence of different variables which interfere in the performance of the automobile assembly line being studied, was previously analysed in Resano et al. [6-10].

$$
\mathrm{n}_{12}+\mathrm{n}_{23}+\mathrm{n}_{34}+\mathrm{n}_{41}=237
$$




$$
\begin{aligned}
& \mathrm{n}_{25}+\mathrm{n}_{56}+\mathrm{n}_{64}+\mathrm{n}_{42}=450 \\
& \mathrm{n}_{37}+\mathrm{n}_{73}=138
\end{aligned}
$$

The fourth closed-loop defines the relationship between the number of pallets with doors in different preassembly states and the number of pallets of cars with disassembled doors via an external variable (x), according to Equation (4). This variable represents the four-door car ratio between the door disassembly stations, located at $\mathbf{M}_{2}$, and the door assembly stations, located at $\mathbf{M}_{4}$. This variable can take on values of between 0 and 1 .

$$
\mathrm{n}_{25}+\mathrm{n}_{56}+\mathrm{n}_{64}+\mathrm{n}_{5}+\mathrm{n}_{6}=\left(\mathrm{n}_{2}+\mathrm{n}_{3}+\mathrm{n}_{4}+\mathrm{n}_{23}+\mathrm{n}_{34}\right) \cdot(1+\mathrm{x})
$$

Where $n_{5}$ and $n_{6}$ are the numbers of stations $M_{5}$ and $M_{6}, n_{2}$ is the number of stations at $M_{2}$; for the door disassembly stations, $\mathrm{n}_{3}$ is the number of stations at $\mathrm{M}_{3}$ and $\mathrm{n}_{4}$ is the number of stations at $\mathrm{M}_{4}$ for the door assembly stations. The values of $\mathrm{n}_{2}, \mathrm{n}_{3}, \mathrm{n}_{4}, \mathrm{n}_{5}$ and $\mathrm{n}_{6}$ remain constant. The following is obtained when replacing the sum of their values in Eq. (4) [6-10]:

$$
\mathrm{n}_{25}+\mathrm{n}_{56}+\mathrm{n}_{64}+60=\left(216+\mathrm{n}_{23}+\mathrm{n}_{34}\right) \cdot(1+\mathrm{x})
$$

\section{The Development of the Model}

The work presented in this article was developed in an Arena simulation environment [11, 12], with the objective of allowing the user to evaluate the performance of the automobile assembly line being studied, through the variation of different parameters, thus contributing to a better definition of the most efficient planning and control system. With this purpose in mind, a decision-making support system was developed, which allows for the automatic generation of different simulation models. This allows the user, at the start of simulation, to interact with the system to be developed through the introduction of various parameters, such as [13-15]: the proportion of four-door car bodies (x); the processing time for each machine; the production sequence based on the type of car (two- or four-door); the speed and length of the intermediate buffers consisting of conveyors; simulation time; the number of pallets circulating on the first 3 loops.

Figure 2 presents the graphic interface which allows the user to set the abovementioned parameters. Furthermore, in the model developed, the reliability of machines was parameterized according to the values referred in Resano [6], regarding average time between failures, as well as the average time of machine stoppage. The aim of using simulation as a decision-making support tool is that of evaluating the performance of a given system during a specific period of time. Most simulation models start off with an empty system and with free resources [16]. For example, a production line usually begins without any parts, be it on the waiting line or on the machines. Thus, since there is no congestion at the start of simulation, the parts enter this empty system and tend to flow at a greater rate, when compared to a real situation where the system is not empty and resources are being used [11, 12]. In fact, the observation gathered during the initial period of simulation will affect the accuracy of the model's performance measurements, leading to the formulation of erroneous conclusions regarding its performance. It is, therefore, important to eliminate this initial period so that the observations gathered do not alter these measurements [17-19]. In accordance with this, and throughout this work, a warm-up period of 56 hours (3360 minutes) was considered, during which the data collected were not considered for statistical purposes. The duration of this time period resulted from the analysis of the behavior of the simulation model developed, since it was then possible to eliminate any aspects that might have interfered in the measurements obtained for performance.

In Resano et al. [6,9] the incompatibility between equations (2) and (5) (see section 2) was demonstrated. This incompatibility reveals that the automobile assembly line cannot operate in practice for $\mathrm{x}<0.37$, in both the stationary and transitory regimes, and for $x>0,97$, in the stationary regime. Through the simulation model developed in the context of this study, and for the automobile production line being analyzed, one also verified that the system did not function for the values of $x<0,37$ and $x>0,97$, due to the phenomena of blockage and starvation occurring on the machines comprising the analyzed model. In the same way, one also observed that, once the minimum buffer capacity mentioned in Resano et al. [6,9] was reached, a continuous supply of transport and assembly pallets to machines was ensured [13]. 


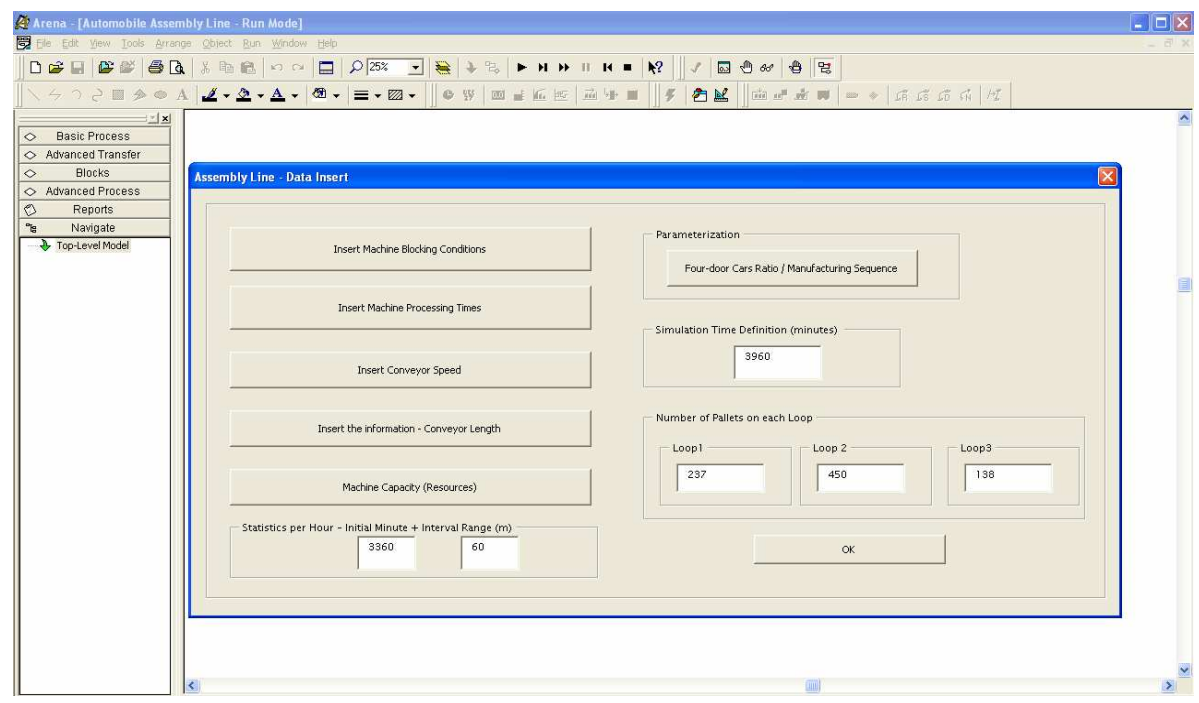

Figure 2. Parameterization of the automobile assembly line

\section{Validation}

As with any simulation project, an important phase is the validation of the model constructed; this assures a faithful representation of reality and can then be used for decision-making. In the context of this work, the validation of the model proposed was confirmed and is based on two presuppositions.

Firstly, as was previously referred in point 3, the results obtained through the simulation model are identical to those obtained by Resano et al. $[6-8,10]$. These demonstrated that the automobile assembly line cannot operate for values of $x<0,37$ and $x>0,97$, due to the incompatibility between equations (2) and (5) (see section 2). Based on this fact, and bearing in mind that simulation models and analytical models are frequently used to validate each other, as can be seen in the work presented by Bulgak et al. [20, 21] and Narahari et al. [22], we considered that the simulation model developed corresponds to a valid representation of reality. The reason for this is that, according to (Narahari and Khan 1996, Bulgak and Sanders 1990) in Hewitt [23], models can be considered to be accurate whenever the results presented by both (the simulation model and the analytical model) do not present differences of more than $5-10 \%$.

Secondly, through the simulation model proposed in this study, one also observed that once the minimum buffer capacity mentioned in Resano et al. [6,9] was reached, a continuous supply of transport and assembly pallets to machines was assured [13]. The two previously mentioned facts reinforce the credibility of the simulation model for the context of this study.

\section{Description of Possible Events}

In the simulation of discrete events, the concept of "event" takes on a vital role since it constitutes the occurrence of an event which alters the state of the system [24]. In the multistage multiproduct line being studied, and with the purpose of gaining a better understanding of its operation, it is important to determine which of the occurrences can be considered "events" since these will be developed on the discrete-event simulation model presented in this work. These will be defined by the operation modes of the line.

Three types of possible events which can be observed on the line were considered:

- Alterations in the operation mode:

- The operation mode changes from the Normal mode to the Full Output mode (if buffer $B_{i j}$ is full, the parts being manufactured upstream on the machine cannot be placed there, thus causing blockage on this machine): Full Output event;

- The operation mode changes from the Normal mode to the Null Output mode (if buffer $B_{i j}$ is empty, there is no supply of parts to the machine downstream, causing starvation on that machine: Null Input event;

- The operation mode changes from the Full Output or Null Input modes to the Normal mode. 
- State of the Machine:

- Introduction of a transport pallet and assembly of car bodies, of doors or front axles, on a machine (the machine stays on Busy state);

- Exit of a transport pallet and assembly of car bodies, of doors or front axles, on a machine (the machine stays on Idle state);

- Failure (breakdown) of the machine (the machine stays on Failed state);

- Blockage of the machine (the machine stays on Inactive state).

- Variation of the position of pallets on the intermediate buffers consisting of conveyors:

- As the pallets move along the buffers, the state of the system changes.

The analysis of events which can take place along the automobile assembly line being studied is one of extreme importance. This is due to the fact that the occurrence of successive Full Output or Null Input events can produce repercussions both upstream and downstream of the point on the line where there was an interruption in flow [25]. Thus, the optimization of the operation of the multistage multiproduct line must necessarily include minimizing Full Output and Null Input events. Furthermore, a state of balance or equilibrium must be established in production flow so as to maximize performance on the line, translated into the number of automobiles produced.

\section{Evaluation of the Impact of the Number of Pallets Circulating on the First Closed-Loop, and of the Proportion of Four-Door Car Bodies, on Production Line Performance}

This study evaluates the performance of the production line when the number of pallets on the first closed-loop is altered. It also assesses the value of external variable x. The results for the simulated scenarios are presented in table I, which contains a flexibility chart for the automobile assembly line based on: the number of pallets circulating on the loop 1, the proportion of four-door car bodies and the number of cars produced per hour.

For each of the scenarios relating to loop 1, the number of pallets circulating on this loop was varied; the number of pallets on the remaining loops was not altered. In the real model, the number of pallets circulating on the first three closed-loops was, respectively, that of 237, 450 e 138.

Table I. Flexibility Chart for the operating Production Line: the number of pallets on Loop 1, the proportion of four-door car bodies and the number of cars / hour

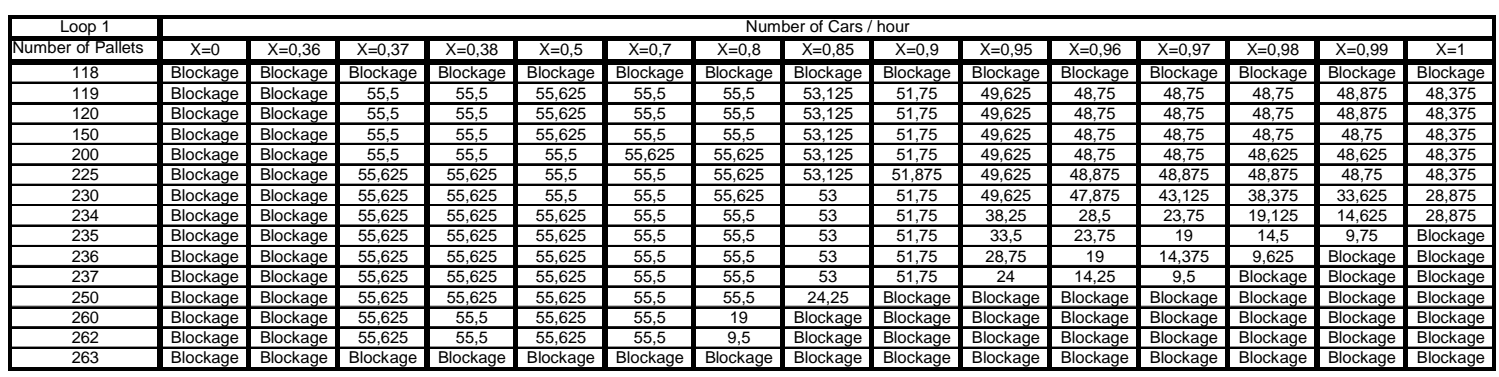

An analysis of the contents of table I allows one to conclude that there will be no blockage on the line for higher values of the four-door car body proportion $(x=1)$, if the number of pallets circulating on loop 1 is within the range $[119,234]$. In the real model, the number of pallets circulating on this loop was that of 237. Thus, one can increase the range of values for external variable $\mathrm{x}$, with which the production line being studied can operate.

Another possible conclusion is that the production line will block whenever the number of pallets circulating on loop 1 is below 119 or above 262. Furthermore, one also observed that the production line blocks when the four-door car body proportion is lower than or equal to 0,36 , regardless of the number of pallets circulating on loop 1 .

A further analysis of table I also allows one to conclude that one can decrease the number of pallets circulating on loop 1 without affecting the performance of the multistage multiproduct production line. This fact has proved to be rather useful since it allows for a reduction of the costs ensuing from a smaller number of circulating pallets. This fact, which has not been mentioned to date in specialist literature, contributes to an improved understanding of the production line studied. 
From the content of table I, the result is figure 3, where one can observe the impact that the variation in the number of pallets circulating on loop 1 causes on the performance of the production line, for a fourdoor car body proportion of, respectively, 0,7, 0,98, 0,99 and 1.
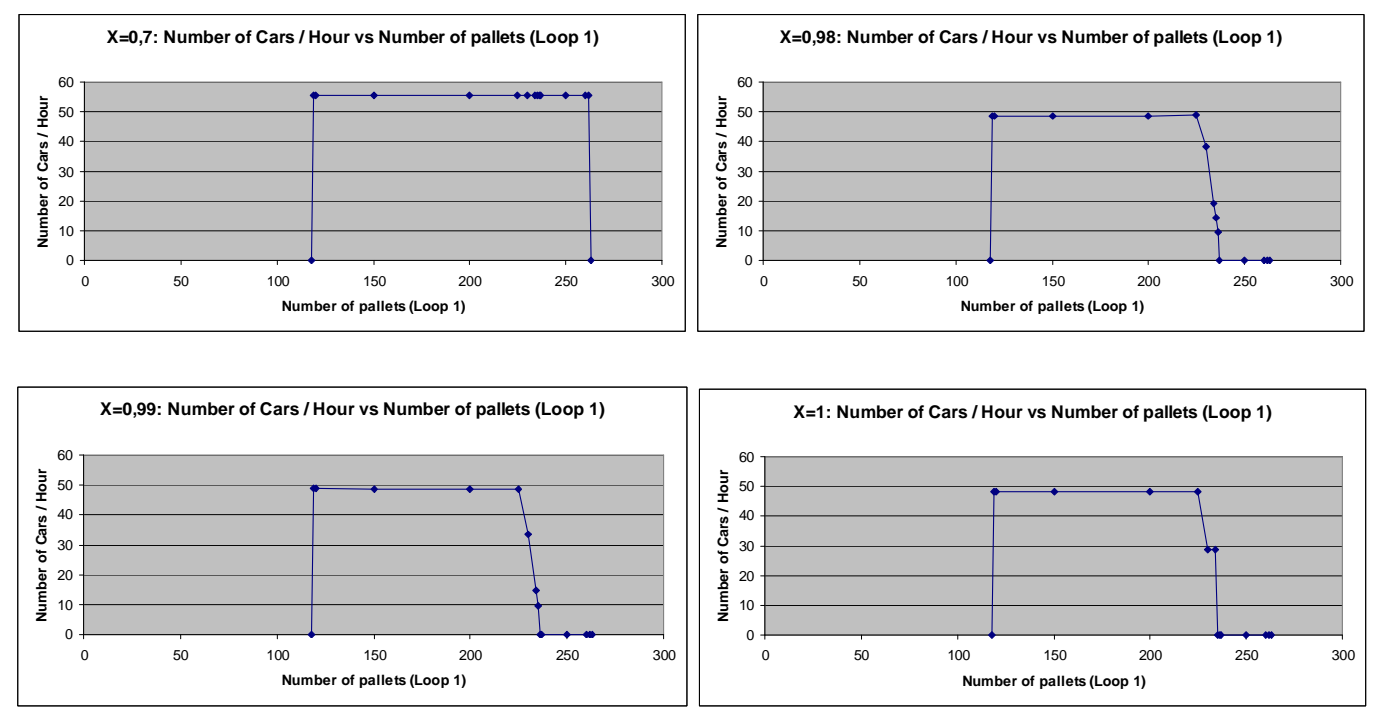

Figure 3. Number of pallets on loop 1, based on the number of cars / hour $(X=0,7 ; X=0,98 ; X=0,99 ; X=1)$

Table II (where PL1 represents the number of pallets circulating on loop 1), and considering the data presented in table I, presents a comparative analysis of the results obtained by Resano et al. [6, 7] through analytical models, with those reached by resorting to the simulation model. On analyzing this, one concludes that the results are very similar and can thus be considered to be accurate.

Table II. Operational limits for the automobile production line, based on the number of pallets circulating on Loop 1 (comparative analysis: analytical model vs simulation model)

\begin{tabular}{|c|c|c|}
\hline \multicolumn{3}{|c|}{ Results } \\
\hline Analytical Model [6, 7] & $\begin{array}{c}\text { Proportion of } \\
\text { four-door car bodies (x) }\end{array}$ & Simulation Model \\
\hline $118 \leq$ PL1 $\leq 235$ & $0,37 \leq \mathrm{x} \leq 0,98$ & $119 \leq$ PL1 $\leq 236$ \\
\hline $118 \leq$ PL1 $\leq 234$ & $0,37 \leq \mathrm{x} \leq 0,99$ & $119 \leq$ PL1 $\leq 235$ \\
\hline $118 \leq$ PL1 $\leq 233$ & $0,37 \leq \mathrm{x} \leq 1$ & $119 \leq$ PL1 $\leq 234$ \\
\hline
\end{tabular}

\section{Evaluation of the Impact of Variable $x$ on the Number of Cars Produced per Hour}

By resorting to the simulation model developed, one sought to evaluate the degree of impact on the number of cars produced per hour for the possible values of external variable $(x)$, which range from $0,37 \leq x \leq 0,97$. In the case of the real model of the production line studied, the reference value for this variable was that of 0,7 .

As can be seen in figure 4, whose content represents the four-door car ratio ( $\mathrm{x}$ ) based on the number of cars/hour, one concludes that, for $\mathrm{x}$ values between 0,37 and 0,81 , the number of cars produced remains constant, with an approximate number of 55,5 cars being produced per hour. However, for values of $\mathrm{x} \geq 0,82$, there is a gradual and significant reduction in the number of cars produced for values of $x \geq 0,91$. 


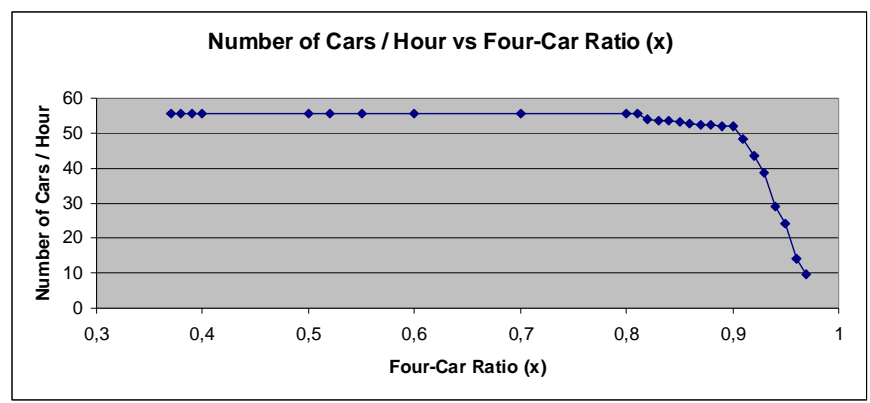

Figure 4. Proportion of four-door car bodies $(x)$ based on the number of cars / hour

\section{Discussion and Conclusions}

In this paper, an automobile assembly line and different preassembly lines were modelled as a network of four closed-loop machines and intermediate buffers formed by conveyors, constituting a configuration which is widely used in these kinds of assembly lines. Using an Arena simulation environment, a representative model of this line was developed, with the purpose of providing the production engineer with a better understanding and assessment of its performance. This paper contributes to the body of knowledge in the following manner:

- It compares the results of the analytical models presented by Resano [6], with those obtained by resorting to the simulation model developed.

- It presents the performance of a production line with a four closed-loop configuration based on the pallet numbers circulating on the first closed-loop.

- It presents the performance of a production line with a four closed-loop configuration based on the four-door car ratio implemented between the door disassembly and assembly stations of the car body.

The most relevant conclusion of the work presented in this article resides in the fact that one can decrease the number of pallets circulating on the first closed-loop without affecting the performance of the multistage multiproduct production line. This fact has proved to be of great use since it allows one to reduce the costs ensuing from a smaller number of circulating pallets. The authors believe that, by producing this study, they have contributed to emphasising the importance of computer simulation use in the development of virtual environments, which reproduce the behaviour of many real systems.

\section{References}

[1] A. Villa, J. E. Ares Gómez, "A methodology to analyze workshop lines by discrete event dynamic models", Agosto de 1987, IXth Internacional Conference on Production Research, Editor: Anil Mital, Páginas 2072-2078, Volume I, Cincinnati, Ohio, U.S.A.

[2] Robert E. Shannon, "Introduction to the Art and Science of Simulation", in Proceedings of 1998 Winter Simulation Conference, D.J.Medeiros, E.F. Watson, J.S. Carson and M.S. Manivannan, eds.

[3] Ricki G. Ingalls, "Introduction to Simulation", in Proceedings of the 2001 Winter Simulation Conference, B.A. Peters, J.S. Smith, D.J. Medeiros, and M. W. Rohrer, eds.

[4] Michael Andersson, Göte Olsson, "A Simulation Based Decision Support Approach For Operational Capacity Planning In A Customer Order Driven Assembly Line", in Proceedings of the 1998 Winter Simulation Conference, D.J.Medeiros, E.F. Watson, J.S. Carson and M.S. Manivannan, eds.

[5] Chrissoleon T. Papadopoulos, Michael E. J. O`Kelly, Michael J. Vidalis, Diomidis Spinellis, "Analysis and Design of Discrete Part Production Lines", 2009, Springer Optimization and Its Applications, Volume 31, ISBN: 978-0-387-89493-5.

[6] A. Resano Lázaro, 2007, "Análisis Funcional y Optimización de la Distribuición en Planta de una Línea de Ensamblaje de Automóviles”, PhD Thesis, directed by Prof. C. J Luis Pérez. Departamento de Ingeniería Mecánica, Energética y de Materiales", Universidad Pública de Navarra.

[7] A. Resano Lázaro, C. J. Luis Pérez, "Analysis and enhancement of the workings limits in an automobile assembly line". 
[8] A. Resano Lázaro, C. J. Luis Pérez, 2007, "Analysis and enhancement of the four-door cars proportion limits in a real automobile assembly line working in transitory regime”, Second Manufacturing Engineering Society International Conference. Madrid. Spain.

[9] A. Resano Lázaro, C. J. Luis Pérez, 2007, "Analysis of an automobile assembly line as a network of closed loops working in both, stationary and transitory regimes". International Journal of Production Research, 1366-588X, Volume 46, Issue 17, 2008, Pages 4803 - 4825.

[10] A. Resano Lázaro, C. J. Luis Pérez, "Dynamic analysis of an automobile assembly line considering starving and blocking", Robotics and Computer Integrated Manufacturing”, Volume 25 Issue 2, April, 2009.

[11] W. David Kelton, Randall P. Sadowski, Deborah A. Sadowski, 2002, "Simulation With ARENA", Second Edition, McGraw-hill Series in Industrial Engineering and Management Science, ISBN 0-07-250739-X.

[12] W. David Kelton, Randall P. Sadowski, David T. Sturrock, 2007, "Simulation With Arena", Fourth Edition, McGraw-hill Series, ISBN-13: 978-0-07-110685-6.

[13] Luís Pinto Ferreira, E. Ares Gómez, G.C Peláez Lourido, A. Resano Lázaro, C. J. Luis Pérez, "Comparative Analysis between analytical and Arena simulation models applied to an Automobile closed-loops assembly line, modelled like a network of closed loops", in Proceedings of $25^{\text {th }}$ International Manufacturing Conference:"Manufacturing and Design - The Next Generation" (IMC2008), Ireland, 3rd-5th September 2008.

[14] Ferreira, L[uís]; E. Ares, G[ómez]; G.C Peláez, L[ourido] \& Salgado, M[arina] (2010). Analysis of the Influence of Conveyor Speed on the Behaviour of an Automobile Assembly Line, Chapter 41 in DAAAM International Scientific Book 2010, pp. 463-470, B. Katalinic (Ed.), Published by DAAAM International, ISBN 978-3-901509-74-2, ISSN 1726-9687, Vienna, Austria.

[15] Luís Pinto Ferreira, Enrique Ares Gómez, Gustavo Peláez Lourido, Marina Salgado, José Diéguez Quintas, "Analysis on the Influence of the Number of Pallets Circulating on an Automobile Closed-Loop Assembly Line", January 2011, International Journal of Advanced Engineering Sciences and Technologies (IJAEST), Volume number 2, Issue number 2, pp. 119-123.

[16] Prasad S. Mahajan, Ricki G. Ingalls, "Evaluation of Methods Used to Detect Warm-Up Period in Steady State Simulation", in Proceedings of the 2004 Winter Simulation Conference, R. G. Ingalls, M. D. Rossetti, J. S. Smith, and B. A. Peters, eds.

[17] Paulo José de Freitas Filho, 2001, "Introdução à Modelagem e Simulação de Sistemas - Com Aplicações em Arena”, Visual Books Editora, ISBN 85-7502-046-3.

[18] Manuel D. Rossetti, Zhe Li, Peng Qu, "Exploring Exponentially Weighted Moving Average Control Charts to Determine the Warm-Up Period", in Proceedings of the 2005 Winter Simulation Conference, M. E. Kuhl, N. M. Steiger, F. B. Armstrong, and J. A. Joines, eds.

[19] Kathryn Hoad, Stewart Robinson, Ruth Davies, "Automating Warm-Up Length Estimation", in Proceedings of the 2008 Winter Simulation Conference, S. J. Mason, R. R. Hill, L. Mönch, O. Rose, T. Jefferson, J. W. Fowler eds

[20] Akif Asil Bulgak, Jerry L. Sanders, "An Analytical Performance Model for Assembly Systems With Automatic Inspection Stations and Repair Loops", Computers \& Industrial Engineering, Volume 18, Issue 3, 1990, Pages 373-380, Elsevier Ltd.

[21] A. A. Bulgak, J. L. Sanders, “Approximate Analytical Performance Models for Automatic Assembly Systems With Statistical Process Control and Automated Inspection “, Journal of Manufacturing Systems, Volume 10, Issue 2, 1991, Pages 121-133, Elsevier Science Ltd.

[22] Y. Narahari, L. M. khan, "Performance Analysis of Scheduling Policies in Re-Entrant Manufacturing Systems”, Computers Ops Res. Vol. 23, No. 1, pp. 37-51, 1996, Elsevier Science, Ltd.

[23] Sara T. Hewitt, "Comparing Analytical and Discrete-Event Simulation Models of Manufacturing Systems”, Master of Science, Institute for Systems Research, University of Maryland, 2002.

[24] Marcos Ricardo Rosa Georges, "Metodologia para Modelagem em Simulação de Sistemas: Aplicação em Manufatura Discreta", 2005, Tese de Doutoramento em Engenharia Mecânica, Departamento de Engenharia de Fabricação, Faculdade de Engenharia Mecânica, Universidade Estadual de Campinas.

[25] A. Matta, M. Runchina, T. Tolio, 2005, “Automated flow lines with shared buffer", Springer-Verlag, OR Spectrum 27:265-286, DOI:10.1007/s00291-005-0197-7. 